\title{
PAISAGEM DO CENTRO DE TERESINA: OS SIGNIFICADOS DOS ELEMENTOS MORFOLÓGICOS
}

\author{
TERESINA'S DOWNTOWN: THE MEANINGS OF THE MORFOLOGICAL PATTERNS
}

\section{CARDOSO, Luciene Brito}

Arquiteta, especialista em ciências ambientais pela UFPI e mestranda do curso de pós-graduação em Desenvolvimento Urbano da UFPE.E-mail: urbana2015@yahoo.com.br

\section{MELO, Vera Mayrinck}

Arquiteta, doutora em geografia humana pela UFRJ, professora da graduação em Arquitetura e Urbanismo e da Pós-graduação em Desenvolvimento Urbano da UFPE. E-mail: veramelo@hotlink.com.br

\section{RESUMO}

Este artigo trata de um recorte da paisagem do centro da cidade de Teresina, capital do Estado do $\mathrm{Pl}$, e abrange o período entre o final da década de 1980, do século XX e o início do século XXI. Neste recorte a paisagem é entendida como o resultado da ação dos diferentes grupos culturais e, de acordo com os fundamentos da nova geografia cultural, possui diferentes significados para aqueles que "a fizeram, a alteraram, a mantiveram, (e) a visitaram". Assim, analisa-se a paisagem do centro de Teresina a partir da interpretação dos significados atribuídos aos elementos morfológicos que constituem esta paisagem pelos grupos culturais que vivenciam o bairro.

Este artigo trata também da importância de incluir a dimensão cultural nas políticas públicas que regulam as intervenções urbanas realizadas no centro de Teresina, de forma a contribuir para a permanência de elementos morfológicos que caracterizam a identidade da cidade.

\section{Palavras-chave: Paisagem, significado, morfologia.}

\begin{abstract}
This article is about the landscape of a part of the city center of Teresina, capital of the Brazilian northeastern state of Piaui, and covers the period between the end of the 1980s and the beginning of the $27^{\text {st }}$ century. In this part, the landscape is understood as a result of the action of different cultural groups and, following the principles of the new cultural geography, it has different meanings for those who "made it, changed it, maintained it, and visited it". Therefore, an analysis of the landscape of the city center of Teresina was made on the basis of an interpretation, by the cultural groups who used to live there, of the significances contributed to the morphological elements that constitute the landscape.

This article also considers the importance of including cultural dimensions in the state policy of urban interventions made in the center of Teresina, in order to maintain the morphologic elements that characterize the identity of the city.
\end{abstract}

Key words: Landscape, significance, morphology.

\section{1 - Introdução}

Os centros urbanos são elementos simbólicos porque congregam história, memória, cargas de afetividade e suas paisagens são hoje o resultado da sobreposição das expressões culturais que se estabeleceram desde as origens das cidades, definidas por valores, crenças e interesses distintos e, por isso, conflitantes. Nestes centros existem elementos morfológicos que definem a singularidade das suas paisagens, e a permanência destes elementos envolve $o$ entendimento dos significados que eles possuem para os grupos culturais ${ }^{7}$ que vivenciam estes locais. Neste sentido, este artigo tem como foco a paisagem do centro de Teresina (Figura 1) a partir da interpretação dos significados atribuídos aos elementos morfológicos que constituem esta paisagem pelos 


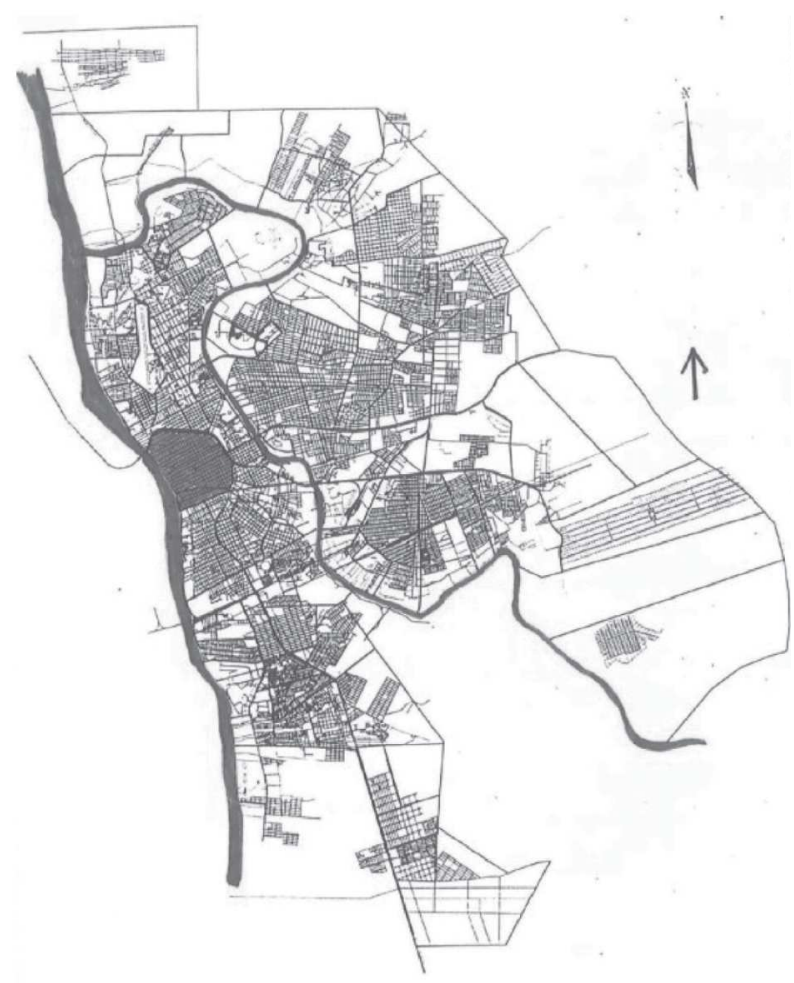

grupos culturais que a vivenciam. Desta forma, a paisagem é entendida como o resultado da ação dos diferentes grupos culturais e possuem diferentes significados para aqueles que " $a$ fizeram, a alteraram, a mantiveram, (e) a visitaram" (COSGROVE, 1988, p. 109).

O interesse por esse tema surgiu após a elaboração do Plano de Desenvolvimento Sustentável - Teresina Agenda 2015², quando se constituiu, em 2003, um grupo para a implementação das propostas definidas no Plano. Este grupo tem como finalidade articular parcerias entre os poderes públicos e privado e com a sociedade civil para a execução dos projetos existentes nessas propostas. Os projetos referentes ao grupo denominado "Revitalização do Centro" geraram grandes conflitos, decorrentes, principalmente, devido à indefinição de um local para a instalação dos comerciantes informais, os camelôs (Figura 2), e à obra de ampliação da linha férrea do metrô (Figura 3), que se estende até a área central da cidade, atendendo aos interesses de apenas uma parcela da população de Teresina. Estes projetos são responsáveis pela transformação das paisagens do centro, tendo em vista a alteração de elementos morfológicos que representam a identidade da cidade.

Desta forma, as intervenções urbanas realizadas do centro de Teresina configuram suas paisagens de acordo com interesses que muitas vezes não representam o interesse da maioria dos grupos culturais que vivenciam este local. Por que então que estes grupos não se envolvem na manutenção destes elementos? Será que para eles é importante que estes elementos permaneçam? A partir destas indagações, questiona-se quais os significados dos elementos morfológicos que configuram a paisagem do centro de Teresina para os diferentes grupos culturais que vivenciam este local. Pois, estes grupos também contribuem para a formação desta paisagem e para a sua transformação através das relações sócio-espaciais ${ }^{3}$ estabelecidas no seu cotidiano.
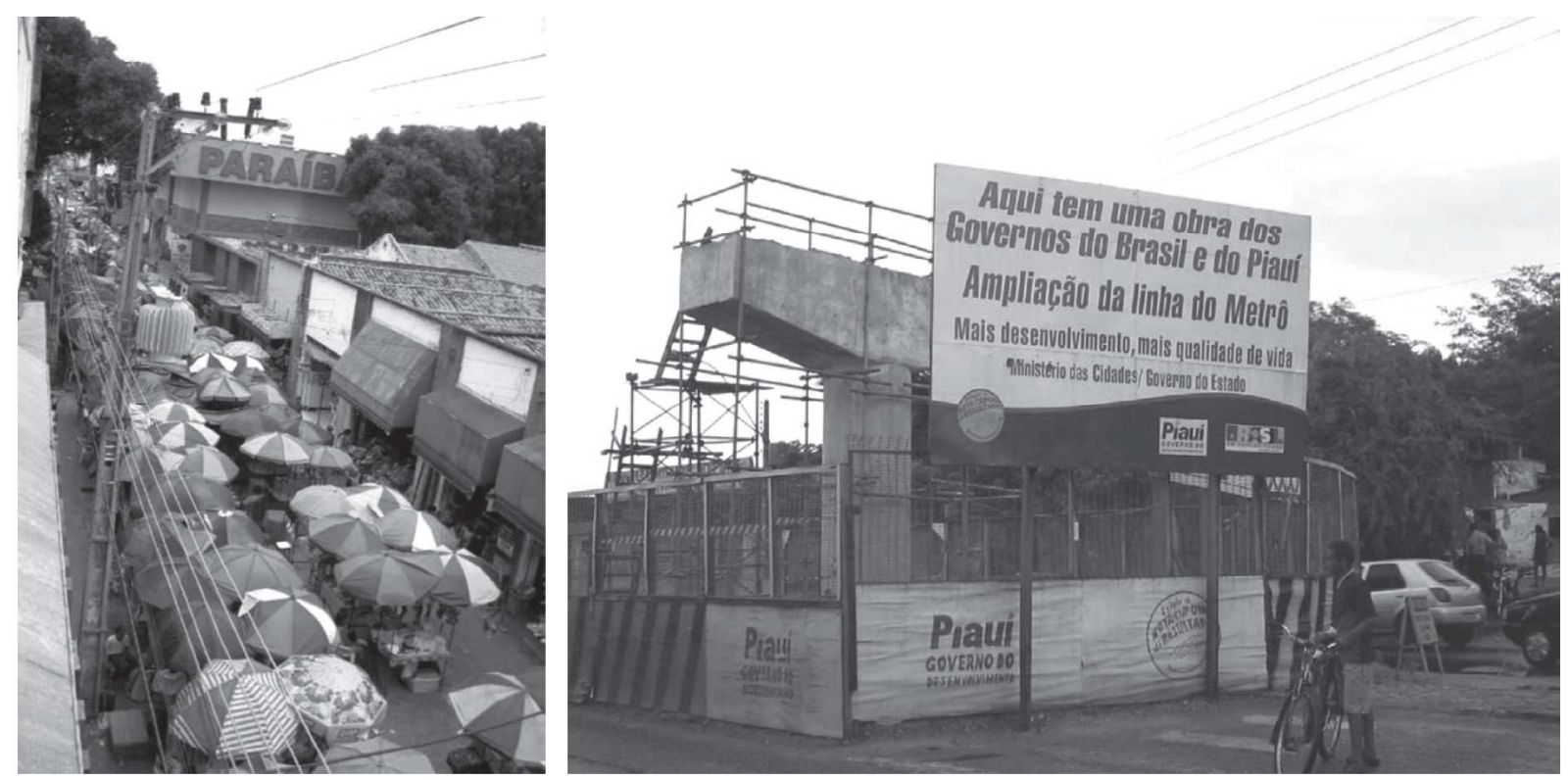
Geralmente as áreas centrais representam os locais iniciais de ocupação das cidades e se estabeleceram através de parâmetros sócio-espaciais diferentes daqueles aplicados posteriormente ao restante da cidade. Isto resulta na importância destas áreas como referenciais de concepção urbana e, também, de memória da cidade (ALMEIDA, 2001, p.71). No entanto, a dinâmica de ocupação das cidades modifica as paisagens das suas áreas centrais tanto na sua forma, quanto nas atividades que abrigam, em conseqüência do atendimento às necessidades dos grupos culturais existentes nas mesmas ao longo do tempo. Estas modificações representam, na maioria das vezes, a expressão dos interesses dos grupos culturais dominantes, pois estes procuram "impor sua própria experiência de mundo, suas próprias suposições tomadas como verdadeiras, como a objetiva e válida cultura para todas as pessoas" (COSGROVE, 1998, p. 104).

Neste sentido, para se compreender as expressões manifestadas por uma cultura em sua paisagem, precisa-se conhecer a "linguagem" empregada através dos símbolos e de seu significado (COSGROVE, 1998, p.105-106). Assim, neste estudo, a paisagem passa a ser abordada tanto pelo seu caráter objetivo, quanto pelo seu caráter subjetivo, onde se inclui a interpretação dos significados. Neste contexto, o processo de construção histórico e cultural dos elementos morfológicos que compõem a paisagem do centro de Teresina foi considerado um componente objetivo, enquanto que os significados dessa paisagem, foram analisados como um aspecto subjetivo.

Este estudo tem, pois, como objeto os significados atribuídos à paisagem do centro de Teresina pelos grupos culturais que o vivenciam. Delimitou-se como recorte espacial, uma área, que compreende 3 (três) zonas de preservação ambiental (ZP) ${ }^{4}$ : a ZP1, a ZP2 e a ZP3 (Figura 4).

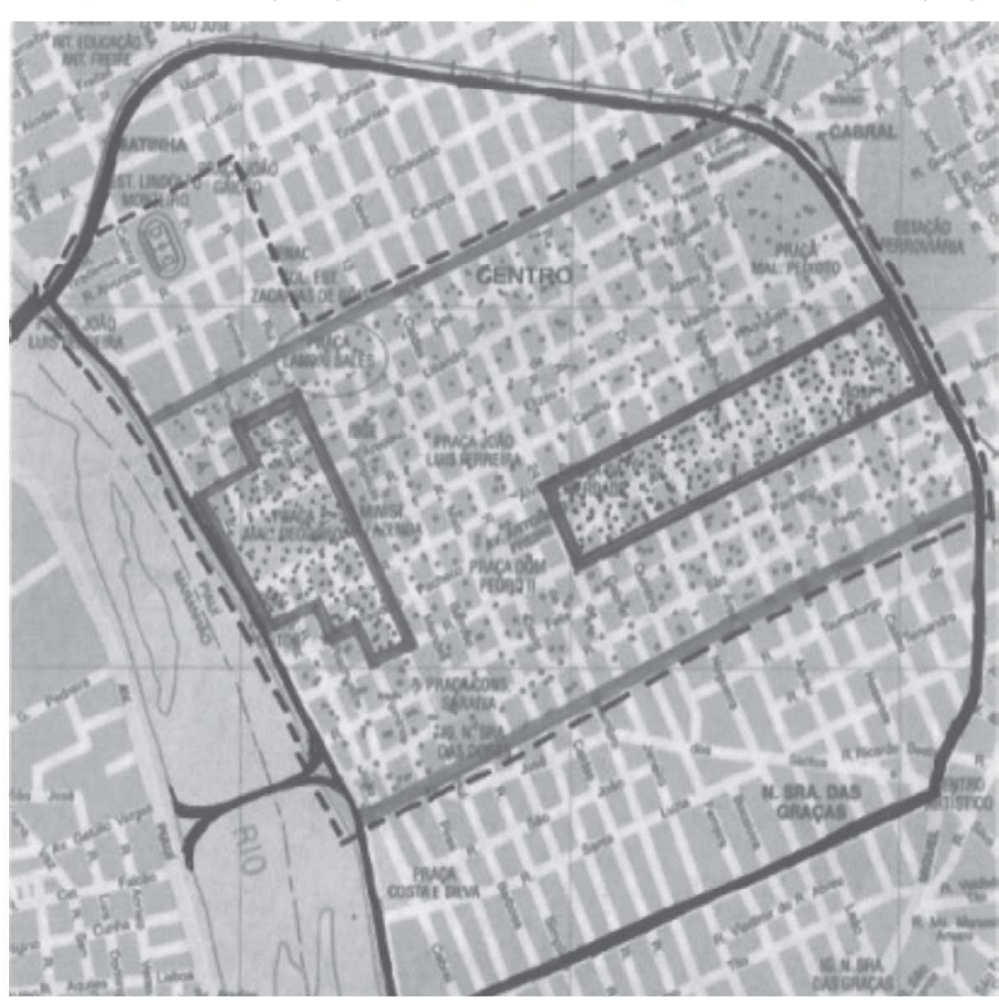

Na delimitação espacial da pesquisa foram utilizados os limites do zoneamento municipal ${ }^{5}$, porque nele se encontram os elementos morfológicos que compõem a paisagem do centro desde o século XIX, e que são referências histórica e cultural para a cidade. O recorte temporal está delimitado entre $\circ$ final da década de 1980, do século XX, e - início do século XXI, pois é partir dessa década que o Poder Municipal amplia as discussões com a sociedade civil para debater as ações a serem implementadas na área central de Teresina. e atualmente se discute as questões, com relação às propostas de intervenção para o bairro, inseridas no Plano de Desenvolvimento Sustentável - Teresina Agenda 2015.

objetivo geral deste estudo é interpretar os significados dos elementos morfológicos que compõem a paisagem do centro de Teresina para os diferentes grupos culturais que vivenciam este local visando a subsidiar as intervenções estabelecidas no referido Plano. E os objetivos específicos são: analisar como se deu o processo de formação da morfologia da paisagem de Teresina, a partir da segunda metade do século $X X$, discorrendo os processos históricos e culturais que a definiram; identificar os tipos de usos existentes no centro; identificar quais os elementos morfológicos que permanecem compondo a paisagem do centro de Teresina e definem a singularidade de sua paisagem e, interpretar os significados destes elementos através 
das "maneiras de ver" dos grupos culturais que vivenciam este centro e participam dos debates sobre a formação de novas paisagens para o bairro.

\section{2 - Metodologia}

Visando a atingir os objetivos propostos adotou-se como referência teórica os conceitos de paisagem cultural, morfologia e significado, baseando-se em procedimentos metodológicos da Nova Geografia Cultural para a interpretação da paisagem e dos seus significados, fundamentado no método Hermenêutico. Com relação à análise morfológica utilizou-se como base tanto os métodos de análise da morfologia urbana, desenvolvidos pelos planejadores urbanos José Garcia Lamas e Luz Pereira Valente, assim como o método de análise da morfologia da paisagem criado pelo geógrafo cultural Carl Ortwin Saver.

Muito da evolução do conceito da paisagem cultural se deve às contribuições de Sauer e suas definições vêm embasar o estudo morfológico da paisagem do centro de Teresina. Saver teve um forte interesse pela história que se fez sentir mais explicitamente quando este adotou o conceito "goethiano" de morfologia que implica a "compreensão das formas enquanto expressão cultural e individual, sendo a manifestação de processos humanos, espirituais e naturais" (CORRÊA, 2001 , p. 11). Esta importância do contexto histórico também foi ressaltada por Lamas (2000, p. 37), que define a morfologia como a ciência que estuda as formas, interligando-as com os fenômenos que lhes deram origem.

Para este autor, o meio urbano é dividido em partes - os elementos morfológicos - que representam as partes físicas que, associadas e estruturadas, constituem a forma (LAMAS, 2000, p. 44). Para definir qual o mínimo elemento morfológico identificável na cidade há que se estabelecer uma hierarquia de valores e fazer uma seleção entre coleções de objetos que povoam - espaço urbano. O elemento mínimo a ser aqui analisado será o edifício, pois, segundo o Lamas (2000, p. 84), "é através dos edifícios que se constitui o espaço urbano e se organizam os diferentes espaços identificáveis e com forma própria, a rua, a praça, o beco, a avenida ou outros espaços mais complexos (...)". Para a análise da paisagem do centro de Teresina, definiram-se os seguintes elementos morfológicos: os edifícios, as praças, o traçado, com suas ruas e pontes e, o rio Parnaíba.

Como procedimentos metodológicos utilizou-se a pesquisa documental e a pesquisa de campo. A pesquisa documental envolve os levantamentos bibliográficos, cartográficos e iconográficos e a coleta de documentos oficiais. Os levantamentos bibliográficos foram coletados em livros que relatam o processo de construção histórico da paisagem do centro de Teresina, identificando-se nos mesmos, assim como no material cartográfico e iconográfico, os elementos morfológicos que constituem essa paisagem. Foram feitas pesquisas em um dos jornais de maior circulação na cidade que contém matérias sobre o bairro, com a finalidade de captar as diferentes "maneiras de ver" o centro dos grupos culturais que o vivenciam, assim como, os conflitos e debates ocorridos na luta para fazer prevalecer os seus interesses. Esses documentos, de acordo com Cosgrove (1998, p.110), constituem-se como "produtos culturais" e foram pesquisados em bibliotecas públicas e privadas.

A coleta de documentos oficiais foi feita com a finalidade de serem analisados projetos de intervenções urbanas, como reformas de praças, adaptação das ruas para a instalação do comércio informal e da construção da linha férrea do metrô e também as leis municipais de uso e ocupação do solo e os instrumentos jurídicos de âmbito municipal relacionados à permanência dos elementos morfológicos definidos para análise. Após a finalização da coleta destes dados iniciais, eles foram compilados e analisados para dar subsídios à pesquisa de campo que foi desenvolvida realizando-se observações in loco e entrevistas. 
As observações têm como objetivo conhecer mais profundamente o recorte do objeto de estudo através da identificação das estruturas urbanas e ambientais e dos grupos culturais que vivenciam o centro de Teresina e os seus representantes que foram entrevistados posteriormente. Para esta etapa utilizou-se o trabalho de Luz Pereira Valente "A análise da imagem de uma área urbana como preparação para o Planeamento/Ação da sua reabilitação". A análise, segundo esse método, realiza-se por observação direta, isto é, percorrer a área, ver e simultaneamente interrogar o que se vê, procurar relacionar, interpretar e avaliar as observações e mapear estas informações, e tem como objetivo verificar as formas atuais de usos e funções dos elementos morfológicos a serem analisados. (PEREIRA, 1999, p. 9). Neste caso a área será a delimitada no objeto de pesquisa, dando ênfase aos elementos morfológicos definidos na "escala do bairro" 6 .

Complementa-se, então a abordagem morfológica com a interpretação dos significados desses elementos e, para isso, realizaram-se entrevistas do tipo semi-estruturadas, objetivando aprofundar as questões inicialmente observadas e elaborou-se uma listagem de questões ou tópicos estruturados de forma a atender aos objetivos da pesquisa. Estes depoimentos orais, também considerados "produtos culturais", têm como finalidade à interpretação dos significados dos elementos morfológicos que compõem a paisagem do centro de Teresina para os grupos culturais, assim como os usos que esses grupos fazem do centro, compreendendo as suas reais necessidades e expectativas com relação aos elementos que compõem esta paisagem. As entrevistas foram gravadas e posteriormente transcritas para interpretação de seus conteúdos.

Por se tratar de uma abordagem qualitativa as entrevistas foram realizadas com um número pequeno de pessoas-chave, representantes dos grupos culturais que discutem junto como o poder municipal as transformações das paisagens do centro, como os representantes das associações e sindicatos existentes. As entrevistas foram realizadas individualmente, dirigidas no sentido de obter uma opinião clara sobre o centro, permitindo que os entrevistados se expressassem livremente. Desta forma, foi entrevistado um representante dos seguintes grupos culturais:

- Grupo 01: Moradores ${ }^{7}$ que foram e são espectadores de muitas transformações na paisagem do centro.

- Grupo 02: lojistas que são proprietários de grande maioria das edificações hoje adaptadas para o comércio.

- Grupo 03: vendedores ambulantes (ou camelôs) que ocupam praças e ruas e passeios públicos através do comércio informal resultando em mudanças de uso destes elementos.

- Grupo 04: motoristas (taxistas e motoristas de ônibus interurbanos) mais antigos que circulam no centro e que assistiram todas as mudanças físicas e de usos das ruas (construção de calçadões, adaptações para o transporte coletivo, instalação de vendedores ambulantes, dentre outras) e possuem registros dos conflitos que estas modificações geraram.

- Grupo 05: representantes do setor de saúde, proprietários de hospitais, que foram responsáveis pela formação de novas paisagens no centro, devido às mudanças no seu entorno, como a adaptação de antigas residências para clínicas médicas, farmácias, laboratórios e pensões.

- Grupo 06: arquitetos e planejadores urbanos, profissionais que através da implantação dos seus projetos arquitetônicos e propostas de urbanização configuram uma nova paisagem para - Centro de Teresina e que atuam em defesa do patrimônio construído do centro.

200 As pesquisas sociais possuem características próprias, com isso, não existe um método único que enquadre todos os tipos de pesquisa, de forma que a criatividade do pesquisador é essencial para a definição da metodologia. Esta constitui um conjunto de regras que possibilitem a construção da realidade e que estabelecem um link entre a fundamentação teórica e os procedimentos de 
campo. Desta forma, estabelece-se para o presente estudo os métodos relatados, ressaltando a importância da interdisciplinaridade para a análise das paisagens urbanas.

\section{A paisagem do centro de Teresina - Formação e debates}

Processo de desenvolvimento de uma cidade relaciona-se com múltiplos fatores econômicos, políticos, sócio-espaciais e culturais e cada uma de suas partes sofre igualmente as conseqüências desses fatores, pois constitui parte de um todo, isto é, o que acontece em uma determinada área da cidade influi sobre todas as outras e com as áreas centrais não tem sido diferente. Segundo Carríon (2002, p. 47), os centros históricos ${ }^{8}$ devem ser entendidos a partir das relações que o configuram e lhes dão sentido e uma destas relações se condiciona a "(...) analisar como tem variado a relação entre o centro histórico, o centro urbano e a cidade, e como a partir dela se evidenciam as assimetrias e distinções, a existência da policentralidade, as relatividades centroperiferia e a mobilidade da centralidade (...)".
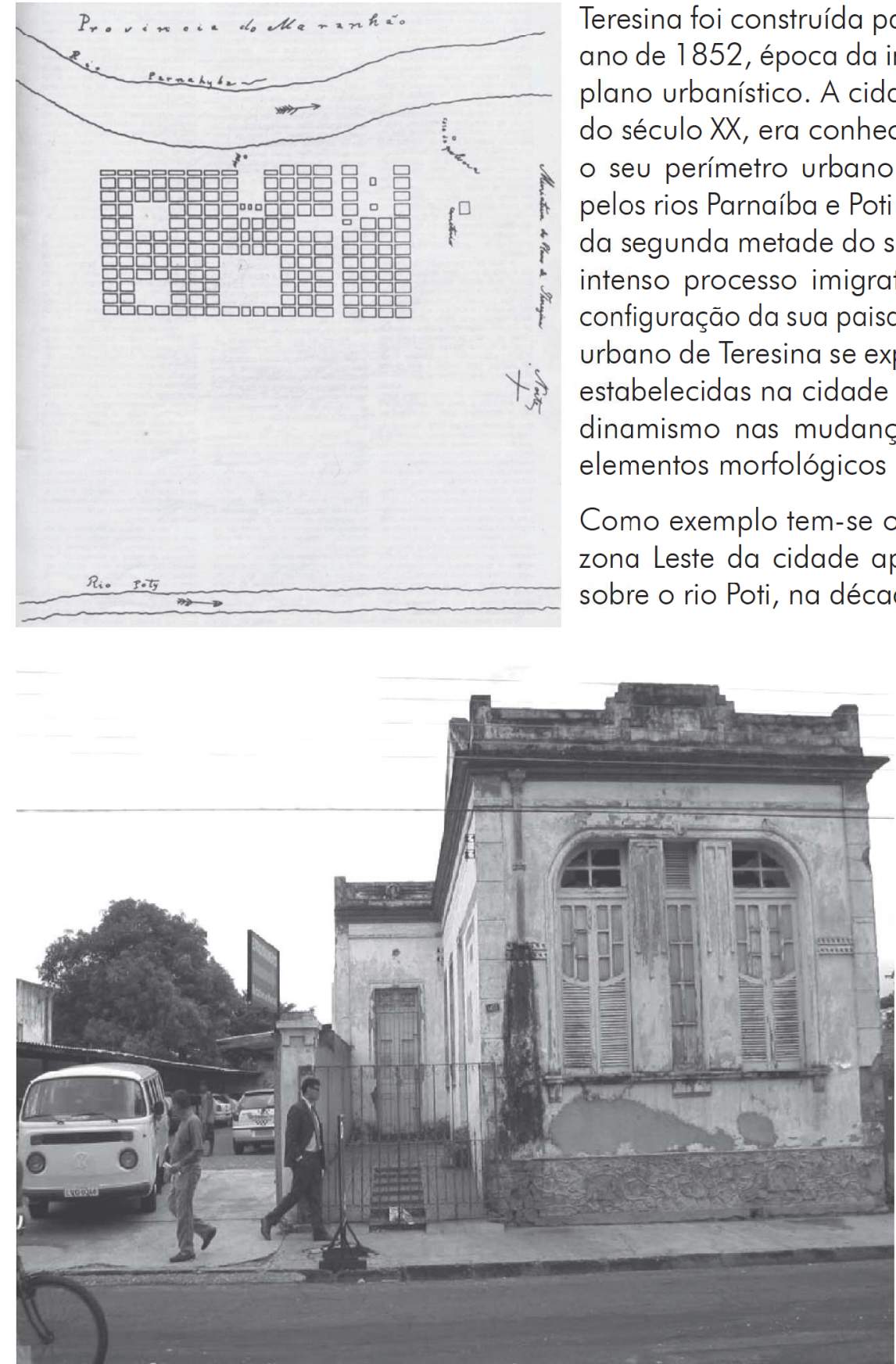

Teresina foi construída para ser a capital do Piauí no ano de 1852, época da implantação do seu primeiro plano urbanístico. A cidade até a década de 1940, do século XX, era conhecida como "entre rios", pois o seu perímetro urbano era praticamente limitado pelos rios Parnaíba e Poti (Figura 5). Somente a partir da segunda metade do século XX, decorrente de um intenso processo imigratório, a cidade modifica a configuração da sua paisagem. Nesta fase o perímetro urbano de Teresina se expande e novas relações são estabelecidas na cidade que resultam em um maior dinamismo nas mudanças de usos e funções dos elementos morfológicos existentes no centro.

Como exemplo tem-se o processo de ocupação da zona Leste da cidade após a construção da ponte sobre o rio Poti, na década de 1950, que favoreceu a criação de uma zona de alto poder aquisitivo. Esta população antes residia no centro da cidade e suas casas foram adaptadas para a instalação de comércios e serviços ou foram demolidas para a construção de estacionamentos privados (Figura 6). Outro processo que resultou em mudanças na paisagem do centro foi a construção de conjuntos habitacionais na periferia da cidade, a partir da década de 1970, resultado de investimentos federais em habitação popular. Este processo favoreceu a criação de novos centros 
de comércios e serviços em conjuntos construídos à longa distância da área central. E, também, na zona Leste foram implantados pequenos shoppings direcionados para uma população de mais alto poder aquisitivo, que culminou com a implantação nesta área, na década de 1990, dos dois maiores shoppings da cidade.

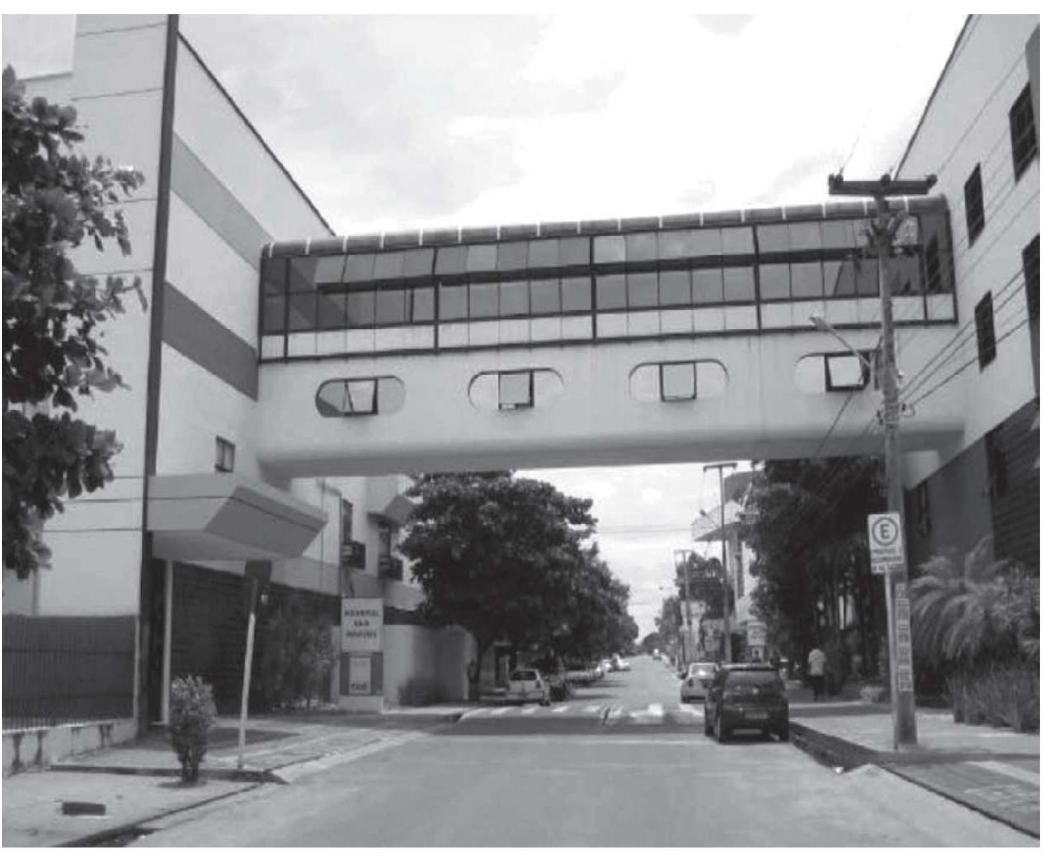

Um outro fator de mudança na paisagem do Centro foi a implantação e o desenvolvimento do Pólo de Saúde (Figura 7), que também alterou o uso das edificações, antes residenciais existentes no bairro. Estas foram adaptadas para a instalação de clínicas médicas, farmácias, laboratórios e pensões para abrigar a população que se desloca do interior do Piauí e de outros Estados em busca de um melhor atendimento médico. Apesar das mudanças nas relações sócio-espaciais existentes no centro, o bairro ainda concentra uma intensa rede de atividades de comércio e serviços, e, mesmo com o deslocamento de muitos moradores para outros bairros, o centro permanece muito freqüentado por uma população de baixo poder aquisitivo. Neste sentido, não se considera que houve um esvaziamento do bairro, mas novos usos dos seus espaços e, conseqüentemente, novas adaptações a estes usos que configuram uma nova paisagem para este local.

Cabe ressaltar que, durante a noite, quando as edificações públicas, de comércios e de serviços estão fechadas e seus espaços públicos vazios, o aumento da insegurança tem sido um forte agravante para que os moradores do bairro sintam-se ameaçados e procurem meios para morar em outro local. Essas mudanças nas relações sócio-espaciais de Teresina, que se refletiram na paisagem do Centro, como o surgimento de novos centros de comércios e serviços nas periferias e, nas zonas de alto poder aquisitivo e no abandono e mudanças de usos das edificações, com a conseqüente descaracterização do patrimônio construído, resultam em conflitos decorrentes dos diferentes interesses nestas formas de ocupação.

Estes conflitos provocaram, a partir do final da década de 1980, do século XX, uma série de debates entre o poder municipal e a sociedade civil formada por grupos de interesses distintos. Em 1989, com a elaboração do diagnóstico do centro de Teresina e a realização do "Fórum sobre o Centro da cidade de Teresina", iniciou-se a realização de seminários e fóruns, nos quais estavam presentes diferentes grupos culturais que participam continuamente destas discussões. No ano 2001, constituiu-se o grupo "Revitalização do Centro", para elaboração do mais recente diagnóstico sobre o centro que embasou as propostas e projetos existentes no Plano de Desenvolvimento Estratégico - Teresina Agenda 2015, que é o instrumento mais atual com diretrizes para as intervenções a serem realizadas no centro.

Dentre os grupos culturais que sempre se posicionaram nestes debates, estão os representantes dos comércios informal e formal. Os camelôs, como são denominados os comerciantes do setor informal, estão presentes de forma significativa, ocupando as praças, as ruas, as "coroas" do rio Parnaíba e o entorno de edificações. Este grupo tem tido conflitos constantes como o setor do comércio formal e os usuários do centro. 
Além dos grupos representados por estes comerciantes, também estão presentes nos debates representantes dos profissionais da área de saúde, que lutam pelo melhor funcionamento do Pólo de Saúde, arquitetos, planejadores urbanos, os motoristas de táxi e de ônibus e os moradores, que vêem a cada dia o abandono do Centro pelos que ali residem.

A partir da análise dos debates existentes entre estes grupos, que resultam em alterações na paisagem do centro de Teresina e, conseqüentemente nos usos dos seus elementos morfológicos, verifica-se que ainda existem grandes conflitos a serem resolvidos. Segundo Melo (2005, p. 12), a "maneira de ver" a paisagem dos grupos dominantes pode até coincidir com as dos outros grupos culturais, mas, em geral, elas são conflitantes. Assim, procura-se aqui encontrar caminhos que permitam chegar aos significados das paisagens, levando em consideração a "maneira de ver" dos grupos culturais como um todo.

\section{4 - Considerações finais}

Segundo Cosgrove (1998, p.101), a paisagem possui "muitas dimensões, oferecendo possibilidades de leituras diferentes e igualmente válidas". Desta forma a paisagem do centro de Teresina, local simbólico, fonte de diversidades culturais e, conseqüentemente, de muitos conflitos, oferece também a possibilidade dessas leituras que precisam ser interpretadas visando a subsidiar futuras intervenções urbanas e ambientais no bairro.

A importância da interpretação dos significados atribuídos às paisagens do centro de Teresina deve-se à necessidade de incluir a dimensão cultural nas intervenções urbanas neste local, contribuindo para a permanência de elementos morfológicos que caracterizam a sua identidade e para suscitar um debate mais amplo sobre as intervenções urbanas e ambientais para que resultem na melhoria da qualidade dos seus ambientes urbanos.

\section{Notas}

(1) O termo "grupo cultural" é utilizado por Saver (1998, p. 59), para o qual a paisagem muda sob a influência de uma determinada cultura, sendo modelada através do tempo por diferentes grupos culturais. E, de acordo com Melo (2003, p. 8), este termo é o mais adequado quando se analisa a paisagem baseando-se em crenças, valores e interesses desses grupos, ou seja, aspectos culturais.

(2) O Plano de Desenvolvimento Sustentável - Teresina Agenda 2015 foi coordenando pelo poder Municipal, entre os meses de agosto de 2001 e agosto de 2002, quando se constituíram dezesseis "grupos temáticos" com a finalidade de elaborar e discutir as propostas deste Plano com a sociedade teresinense.

(3) Segundo Côrrea, a sociedade só se torna concreta a partir de seu espaço e, por outro lado, o espaço só e inteligível através da sociedade, então não há porque falar em sociedade e espaço como se fossem coisas separadas. Desta forma, a formação sócio-espacial é considerada pelo autor como uma meta-conceito, "um paradigma que contém e está contido nos conceitos-chave de natureza operativa, paisagem, região, espaço (organização espacial), lugar e território."

(4) As Zonas de Preservação Ambiental (ZP) foram criadas pela Lei Municipal n. 1939 de 16 de agosto de 1988, a qual "institui normas de proteção dos bens de valor cultural e dá outras providências".

(5) $\bigcirc$ zoneamento municipal representa a expressão de um determinado grupo cultural, os planejadores urbanos, que receberam influência do funcionalismo. Segundo Lamas (2002, p. 303), "a lógica funcionalista zonifica a cidade por funções e determina a concepção urbana, por sistemas independentes (...) A consequência desse processo será a autonomização e independência física dos vários sistemas entre si, ou seja, os vários elementos que estruturam a cidade deixarão de se relacionar espacial e tormalmente".

(6) As escalas ou dimensões da forma urbana são classificadas, segundo Lamas (2002, p. 73-74), em dimensão setorial (a escala da rua), a escala urbana (a escala do bairro) e a dimensão territorial (a escala da cidade) e a partir da escala do bairro é "que existe verdadeiramente a área urbana, a cidade ou parte dela".

(7) Dentre os grupos culturais entrevistados apenas os moradores não eram organizados em torma de sindicato e associação, neste caso foram selecionados para entrevista os moradores mais antigos.

(8) O termo "centro histórico" é utilizado pelo autor, mas considera-se aqui cada parte da cidade como histórica, apenas dá-se ênfase aos centros porque, na maioria das cidades, ainda possuem registro de elementos morfológicos da sua paisagem à época da construção da cidade, como algumas edificações e espaços públicos. 


\section{Bibliografia}

CARRÍON, Femando. Vinte temas sobre os centros históricos da América Latina. In: ZANCHETI, Sílvio Mendes (Org.). Gestão do patrimônio integrado. Recife: Universidade Federal de Pernambuco, 2002. p. 45-58.

CORRÊA, Roberto Lobato. Carl Sauer e a Escola de Berkeley - Uma apreciação. In: CORRÊA, Roberto Lobato; ROSENPAHL, Zeny (Orgs.). Matrizes da geografia cultural. Rio de Janeiro: EdUERJ, 2001. p. 9-34 (Série Geografia Cultural).

COSGROVE, Denis. A geografia cultural está em toda parte: cultura e simbolismo nas paisagens humanas. In: CORRÊA, Roberto Lobato; ROSENDAHL, Zeny (Orgs). Paisagem, tempo e cultura. Rio de Janeiro: EdUERJ, 1998. p. 92-123.

LAMAS, José M. Ressano Garcia. Morfologia urbana e desenho da cidade. 2. ed. Lisboa: Fundação Calouste Gulbenkian: Junta Nacional de Investigação Científica e Tecnológica, 2000.

MELO, Vera Mayrinck de Oliveira. Um recorte da paisagem do rio Capibaribe: Seus significados e representações. Tese (Doutorado em Geografia). Universidade Federal do Rio de Janeiro. Rio de Janeiro, 2003.

PEREIRA, Luz Valente. A leitura da imagem de uma área urbana como preparação para o planeamento/ação de sua reabilitação. Lisboa, Informação Técnica, Planeamento Urbano e Regional, 1986.

SAUER, Carl. A morfologia da cidade. In: CORRÊA, Roberto Lobato; ROSENDAHL, Zeny (Orgs). Paisagem, tempo e cultura. Rio de Janeiro: EdUERJ, 1998. p 12-74. 